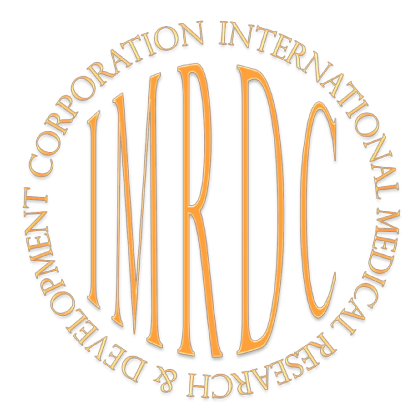

\title{
Effects of the Presence of Left Main Coronary Artery Disease on the Results of Off-pump Coronary Artery Bypass Grafting Surgery
}

\author{
Islamjan M. Sharipov, PhD*; Rustam R. Yarbekov, PhD; Sanjar Kh. Omonov, PhD; \\ Tahir Z. Vahidov; Ravshanbek D. Kurbanov, PhD, ScD \\ Republican Specialized Centre of Cardiology \\ Tashkent, Uzbekistan
}

\begin{abstract}
Background: Left main coronary artery (LMCA) disease is one of the risk factors that affect the outcomes of coronary artery bypass grafting surgery. In particular, this risk factor pertains to the conduct of conventional on-pump CABG. Very little is known about the effects of the presence of LMCA disease on the results of off-pump CABG (OPCABG) surgery.

Material and Methods: In the Department of Cardiac Surgery of the Republican Specialized Center of Cardiology, during the period between April 2015 and April 2017, 270 consecutive OPCABG procedures were performed. Patients were divided into 2 groups depending on the presence or absence of LMCA disease. Group 1 consisted of 124(44.9\%) patients with LMCA disease, and Group 2 consisted of 146(55.1\%) patients without LMCA lesions (non-LMCA group).

Results: The average number of distal anastomoses in both groups was more than 3 anastomoses/patient. The incidence of nonfatal intraoperative complications was $8.9 \%$ in Group 1 and $15.1 \%$ in Group $2(P=0.1212)$. The conversion rate to on-pump CABG amounted to $3.2 \%$ (4 patients) in Group 1 and to $4.8 \%$ (7 patients)in Group 2. In the immediate postoperative period, 40(32.2\%) patients of Group 1 and 45(30.8\%) of Group 2 needed inotropic support until full restoration of normal hemodynamics with duration between 3.0 and 2.6 hours. The average duration of ventilation support was 6.4 hours in Group 1 and 5.6 hours in Group 2. Hospital mortality was $0.8 \%$ (1 patient) in Group 1 and $0.7 \%$ (1 patient) in Group 2.

Conclusion: Thus, the presence of left main stem lesion of LCA is not an additional risk factor that would complicate the performance of OPCABG surgery. The OPCABG operation in this group of patients is a safe method and can be performed without compromising the completeness of myocardial revascularization with the same low mortality as in low-risk patients. (International Journal of Biomedicine. 2017;7(3):175-179.)
\end{abstract}

Key Words: off-pump CABG • left main coronary artery • surgical technique $\bullet$ myocardial revascularization

\section{Abbreviations}

AF, atrial fibrillation; ACS, acute coronary syndrome; CABG, coronary artery bypass grafting; COPD, chronic obstructive pulmonary disease; DM, diabetes mellitus LAD, left anterior descending artery; LCA, left coronary artery; LMCA, left main coronary artery; LIMA, left internal mammary artery; LVEF, left ventricular ejection fraction; LVEDD, LV end-diastolic diameter; LVEDV, LV end-diastolic volume; MI, myocardial infarction; OPCABG, off-pump CABG; PDA, posterior descending artery; PCI, percutaneous coronary intervention; PVCs, premature ventricular contractions; RIMA, right internal mammary artery; RCA, right coronary artery; VT, ventricular tachycardia; VF, ventricular fibrillation.

\section{Introduction}

Left main coronary artery (LMCA) disease is one of the risk factors that affect the outcomes of coronary artery bypass

*Corresponding author: Islamjan Sharipov, PhD. Department of Cardiac Surgery, Republican Specialized Centre of Cardiology. Tashkent, Uzbekistan.E-mail: islamsharipov@mail.ru grafting surgery. In particular, this risk factor pertains to the conduct of these operations with cardio-pulmonary bypass and cardioplegia - conventional on-pump CABG. Very little is known about the effects of the presence of LMCA disease on the results of OPCABG surgery. Given all of the above, it seemed to us beneficial to conduct additional research in this area. In this regard, we would like to present our results from performing OPCABG surgery on patients with LMCA disease. 


\section{Material and Methods}

In the Department of Cardiac Surgery of the Republican Specialized Center of Cardiology, during the period between April 2015 and April 2017, 270 consecutive OPCABG procedures were performed (this accounted for $90 \%$ of the total number of 300 patients who underwent isolated $\mathrm{CABG}$ operations).

The study protocol was reviewed and approved by the Ethics Committee of the Republican Specialized Centre of Cardiology. All participants provided the written informed consent. Patients were divided into 2 groups depending on the presence or absence of LMCA disease. Group 1 consisted of $124(44.9 \%)$ patients with LMCA disease, and Group 2 consisted of $146(55.1 \%)$ patients without LMCA lesions (non-LMCA group). Examination of clinical and demographic indicators in the groups (Table 1) showed that the distribution of patient characteristics in both groups was relatively homogeneous.

Table 1.

Preoperative demographics and clinical data

\begin{tabular}{|l|c|c|c|}
\hline \multicolumn{1}{|c|}{ Variable } & $\begin{array}{c}\text { Group 1 } \\
(\mathrm{n}=124)\end{array}$ & $\begin{array}{c}\text { Group 2 } \\
(\mathrm{n}=146)\end{array}$ & $P$-value \\
\hline Sex, M/F & $\begin{array}{c}\text { M - 102 (82.2\%) } \\
\text { F - 22 (17.7\%) }\end{array}$ & $\begin{array}{c}\text { M-122 (83.6\%) } \\
\text { F- 24 (16.4\%) }\end{array}$ & 0.7759 \\
\hline Age, years & $60.2 \pm 9.3$ & $59.3 \pm 6.3$ & 0.3469 \\
\hline Obesity & $40(32.2 \%)$ & $59(40.4 \%)$ & 0.1659 \\
\hline COPD & $24(19.4 \%)$ & $54(37.0 \%)$ & 0.0014 \\
\hline DM & $38(30.6 \%)$ & $52(35.6 \%)$ & 0.3877 \\
\hline Chronic renal failure & $7(5.6 \%)$ & $15(10.3 \%)$ & 0.1658 \\
\hline History of MI & $95(76.6 \%)$ & $107(73.3 \%)$ & 0.5307 \\
\hline ACS & $31(25.0 \%)$ & $13(8.9 \%)$ & 0.0003 \\
\hline History of PCI & $9(7.2 \%)$ & $9(6.2 \%)$ & 0.7195 \\
\hline LV EDD, mm & $56.7 \pm 7.7$ & $57.3 \pm 7.9$ & 0.5298 \\
\hline LV EDV, ml & $165.4 \pm 60.3$ & $166.3 \pm 58.3$ & 0.9011 \\
\hline LV EF, $\%$ & $54.5 \pm 10.1$ & $54.9 \pm 10.1$ & 0.7460 \\
\hline LV EF<45\% & $24(19.4 \%)$ & $24(16.4 \%)$ & 0.5323 \\
\hline NYHA III-IV & $119(96.0 \%)$ & $126(86.3 \%)$ & 0.0063 \\
\hline Angina class CCA III & $60(48.4 \%)$ & $89(61.0 \%)$ & 0.0384 \\
\hline Angina class CCA IV & $64(51.6 \%)$ & $57(39.0 \%)$ & 0.0384 \\
\hline EuroScore add & $4.32 \pm 2.6$ & $3.43 \pm 2.7$ & 0.0065 \\
\hline EuroScore log & $4.63 \pm 4.8 \%$ & $3.83 \pm 4.0 \%$ & 0.1364 \\
\hline
\end{tabular}

The majority of patients were male $-82.2 \%$ in Group 1 and $83.6 \%$ in Group 2. The mean age of patients was 60.2 and 59.3 years, respectively. More than two-thirds of patients in each group had a previous history of MI. DM was recorded in $30.6 \%$ of patients in Group 1 and in $35.6 \%$ of patients in Group 2. Chronic kidney disease stages 1 to 3 was identified in $5.6 \%$ and $10.3 \%$ of patients in Groups 1 and 2, respectively. Coronary artery stenting (PCI) in the anamnesis was performed in $7.3 \%$ and $6.2 \%$ of patients in Groups 1 and 2, respectively.
COPD was found in $36.9 \%$ of cases in Group 2 vs. $19.3 \%$ of cases in Group $1(P=0.0014)$. ACS was found in $25 \%$ of cases in Group 1 vs. $8.9 \%$ of cases in Group $2(P=0.003)$. Left ventricular measurements from echocardiography and LVEF were similar in both groups. LVEF was less than $45 \%$ in $19.4 \%$ and $16.4 \%$ of patients in Groups 1 and 2, respectively. The majority of patients in both groups were in NYHA functional classes III and IV (95.9\% and 86.3\%, respectively). Group 1 included more patients with unstable and severe angina $(51.6 \%$ compared to $39.1 \%$ in Group 2, respectively, $P=0.0384$ ). The risk of surgical intervention, calculated with a EuroScore risk calculator, was greater in patients of Group $1-4.32 \pm 2.6$ while in Group 2 it was $3.43 \pm 2.7(P=0.0065)$. Nevertheless, for the majority of parameters, both groups were homogeneous.

\section{Surgical Technique}

We used standard anesthesia monitoring and, in addition to conventional general anesthesia, the technique of high thoracic epidural analgesia. All operations were performed from the median sternotomy. In all patients, the left internal thoracic (or mammary) artery (LIMA) was harvested. When it was not possible to use the LIMA, we harvested the RIMA. In parallel, the great saphenous vein was harvested. Heparin was administered at a dose of 1 to $1.5 \mathrm{mg} / \mathrm{kg}$ of patient weight (until ACT value $>300 \mathrm{sec}$ ). The pericardium was opened in a standard inverted " $\mathrm{T}$ " fashion. In all cases, a deep pericardial suture (LIMA stitch) was used, by manipulation of which we could access various surfaces of the heart. If necessary (in case of problems with visualization of the lateral surface of the heart for access to the branches of the circumflex artery $(\mathrm{Cx})$ ), we applied additional deep pericardial sutures near the orifices of the left upper and lower pulmonary veins. We also used commercially available heart positioners (Starfish, Medtronic Minneapolis, MN). To stabilize the myocardium of the heart in the field of anastomosis, we used commercially available tissue stabilizers (Octopus 4 Tissue Stabilizer, Medtronic, Minneapolis, MN). Temporal occlusion of the coronary artery was performed by applying a silicone vessel loop to the proximal part of artery. After performing an arteriotomy, always, if possible, intra-coronary shunts were used(ClearView Intracoronary Shunt; Medtronic). Revascularization was initiated from an occluded recipient artery. Usually it was either LAD or RCA (or PDA). In cases where it was LAD, first LIMA-LAD anastomosis was constructed and then continued in the usual manner. If it was an RCA (or PDA), then at first a distal anastomosis with the vein was constructed. Then all proximal anastomoses were constructed on the ascending aorta using a side-bite clamp, and blood supply was restored to the RCA region. This was followed by revascularization of the $\mathrm{LAD}$ region. Arteries of the lateral side of the heart $(\mathrm{Cx}$ artery region) were revascularized only after the arteries of the anterior surface (LAD and RCA regions) had been revascularized and received a blood supply. If there were no occluded arteries, revascularization was always initiated with the LAD artery. After completion of the construction of all grafts, flowmetry (Transit-time flow measurement) was performed to assess the quality of anastomoses (MiraQ, Medistim, Norway). If there was no excess bleeding, we neutralized only half the dose of heparin. 
Statistical analysis was performed using the statistical software SPSS 16.0 (SPSS Inc., Chicago, IL, USA). Baseline characteristics were summarized as frequencies and percentages for categorical variables and as mean $\pm \mathrm{SD}$ for continuous variables. For data with normal distribution, inter-group comparisons were performed using Student's t-test. Group comparisons with respect to categorical variables are performed using chi-square tests with Yates correction or, alternatively, Fisher's exact test when expected cell counts were less than 5. Two-tailed $P$ values $<0.05$ were considered statistically significant.

\section{Results}

Intraoperative data for groups are presented in Table 2.

Table 2 .

\section{Intraoperative data}

\begin{tabular}{|l|c|c|c|}
\hline \multicolumn{1}{|c|}{ Variable } & $\begin{array}{c}\text { Group 1 } \\
(\mathrm{n}=124)\end{array}$ & $\begin{array}{c}\text { Group 2 } \\
(\mathrm{n}=146)\end{array}$ & $P$ \\
\hline Operation times. min & $255.14 \pm 55.0$ & $264.8 \pm 56.1$ & 0.1560 \\
\hline $\begin{array}{l}\text { Usage of the left internal } \\
\text { thoracic artery (or the right) }\end{array}$ & $124(100 \%)$ & $146(100 \%)$ & 1 \\
\hline $\begin{array}{l}\text { Distal anastomoses, } \\
\text { per patient }\end{array}$ & $3.07 \pm 0.7$ & $3.02 \pm 0.8$ & 0.5884 \\
\hline 3 grafts & $69(55.6 \%)$ & $81(55.5 \%)$ & 0.9748 \\
\hline 4 grafts & $29(23.4 \%)$ & $26(17.8 \%)$ & 0.2566 \\
\hline Sequential technique & $9(7.3 \%)$ & $22(15.1 \%)$ & 0.0448 \\
\hline $\begin{array}{l}\text { Composite grafts (“T”, } \\
\text { "Y"-grafts etc.) }\end{array}$ & $18(14.5 \%)$ & $9(6.2 \%)$ & 0.0226 \\
\hline "LIMA first” technique & $86(69.4 \%)$ & $121(82.9 \%)$ & 0.0088 \\
\hline "non LIMA first" technique & $38(30.6 \%)$ & $25(17.1 \%)$ & 0.0088 \\
\hline Blood loss. ml & $596.4 \pm 228.5$ & $554.6 \pm 197.6$ & 0.1082 \\
\hline $\begin{array}{l}\text { Intraoperative complications: } \\
\text { Frequent PVC } \\
\text { AF. VT. VF } \\
\text { Need for inotropic support }\end{array}$ & $\begin{array}{c}11(8.9 \%) \\
0\end{array}$ & $\begin{array}{c}22(15.1 \%) \\
2(1.4 \%)\end{array}$ & 0.1212 \\
\hline Conversion to on-pump & $4(3.3 \%)$ & $\begin{array}{c}13(8.9 \%) \\
7(4.8 \%)\end{array}$ & \\
\hline
\end{tabular}

The mean duration of the procedure was about 255 minutes in Group 1 and 264 minutes in Group 2. In both groups, LIMA (or RIMA) was used in all patients. The average number of distal anastomoses in both groups was more than 3 anastomoses/patient. In about $75 \%-80 \%$ of all patients, 3-4 grafts were constructed. In approximately $21 \%-22 \%$ of patients in both groups, we used a complex surgical technique in the form of sequential and composite grafts. In Group 2, the sequential grafting technique was used more frequently ( $15.1 \%$ vs. $7.3 \%$ in Group 1), while in Group 1 we constructed more composite grafts $(14.5 \%$ vs. $6.2 \%$ in group 2$)$. As we indicated earlier, the sequence of grafting varied depending on the presence or absence of occluded arteries. In accordance with this, initiation of revascularization with the LAD artery accounted for $69.4 \%$ in Group 1 and $82.9 \%$ in Group 2 $(P=0.0088)$. In the remaining cases, grafting began from other territories (as a rule, it was the RCA region). Mean blood loss in both groups did not differ and amounted to $596 \mathrm{ml}$ and $554 \mathrm{ml}$, respectively. The incidence of nonfatal intraoperative complications was $8.9 \%$ in Group 1 and $15.1 \%$ in Group 2. As a rule, frequent PVCs, paroxysm of $\mathrm{AF}$ during intraoperative period, and hemodynamic collapse, which required the initiation of vasopressors, were the prevailing complications. The conversion rate to on-pump CABG amounted to $3.2 \%$ (4 patients) in Group 1 and to $4.8 \%$ (7 patients) in Group 2 $(P=0.5159)$.

In the immediate postoperative period (Table 3), $40(32.2 \%)$ patients of Group 1 and 45(30.8\%) of Group 2 $(P=0.8002)$ needed inotropic support until full restoration of normal hemodynamics with duration between 3.0 and 2.6 hours. The average duration of ventilation support was 6.4 hours in Group 1 and 5.6 hours in Group 2. One patient in Group 1 required prolonged ventilation for more than 24 hours, while there were no such complications among the patients of Group 2.

Table 3.

Postoperative data

\begin{tabular}{|l|c|c|c|}
\hline \multicolumn{1}{|c|}{ Parameter } & $\begin{array}{c}\text { Group I } \\
(\mathrm{n}=124)\end{array}$ & $\begin{array}{c}\text { Group II } \\
(\mathrm{n}=146)\end{array}$ & $P$ \\
\hline Need for inotropic support & $40(32.2 \%)$ & $45(30.8 \%)$ & 0.8002 \\
\hline Inotropic support time, hours & $3.0 \pm 6.57$ & $2.6 \pm 6.15$ & 0.6062 \\
\hline Ventilation time, hours & $6.4 \pm 4.1$ & $5.6 \pm 3.1$ & 0.0694 \\
\hline $\begin{array}{l}\text { Prolonged ventilation, } \\
>24 \text { hours }\end{array}$ & $1(0.8 \%)$ & 0 & 0.4592 \\
\hline RBC transfusion, ml & $347.1 \pm 182.0$ & $338.7 \pm 162.5$ & 0.6891 \\
\hline FFP transfusion, ml & $432.2 \pm 135.5$ & $422.2 \pm 132.7$ & 0.5412 \\
\hline AF & $7(5.6 \%)$ & $9(6.2 \%)$ & 0.8580 \\
\hline Chest re-open for hemostasis & $2(1.6 \%)$ & $1(0.7 \%)$ & 0.5954 \\
\hline Superficial wound infection & $1(0.8 \%)$ & $1(0.7 \%)$ & 1 \\
\hline Perioperative MI & $1(0.8 \%)$ & $1(0.7 \%)$ & 1 \\
\hline Neurologic complications & 0 & $1(0.7 \%)$ & 1 \\
\hline Length of stay in ICU, hours & $53.6 \pm 19.4$ & $52.1 \pm 20.8$ & 0.5431 \\
\hline $\begin{array}{l}\text { Length of hospital stay } \\
\text { after surgery, days }\end{array}$ & $6.2 \pm 1.4$ & $6.9 \pm 3.4$ & 0.0330 \\
\hline Mortality & $1(0.8 \%)$ & $1(0.7 \%)$ & 1 \\
\hline
\end{tabular}

$R B C=$ red blood cells; $F F P=$ fresh frozen plasma.

Patients of both groups received hemo- and plasmatransfusions when necessary, intraoperatively and/or in the postoperative period. Thus, patients of Groups 1 and 2 received on average $347.1 \mathrm{ml}$ and $338.7 \mathrm{ml}$ of erythrocyte mass, respectively ( $P=0.6891$ ), as well as on average $432.2 \mathrm{ml}$ and $422.2 \mathrm{ml}$ per patient of fresh frozen plasma, respectively $(P=0.5412) . \mathrm{AF}$, a complication of the postoperative period, was noted in $5.6 \%$ of patients in Group 1 and in $6.2 \%$ in Group $2(P=0.8580)$. All paroxysms of AF in the postoperative period passed without serious hemodynamic compromise and were treated medically.

In one patient $(0.7 \%)$ of Group 2, there was an episode of transitory ischemic attack without neurologic deficit, while 
in Group 1 such complications were not noted. Perioperative MI was noted for one patient in each group $(0.8 \%$ and $0.7 \%$, respectively). In the postoperative period, two patients $(1.6 \%)$ in Group 1 and one patient $(0.7 \%)$ in Group 2 underwent reexploration of the mediastinum for hemostasis. In Groups 1 and 2, superficial wound infection was noted in $0.8 \%$ and $0.7 \%$ of cases, respectively $(P=1)$.

The average length of stay in the surgical ICU was 53.6 hours in Group 1 and 52.1 hours in Group $2(P=0.5431)$. The average length of the hospital stay after the procedure was 6.2 days for patients in Group 1 and 6.9 days in Group 2 $(P=0.0330)$. Hospital mortality was $0.8 \%$ in Group 1 and $0.7 \%$ in Group $2(P=1)$.

\section{Discussion}

Since the beginning of the era of coronary surgery, surgeons have had a special attitude towards the patients with LMCA disease, which was expressed in special requirements for preoperative tactics, anesthesia, surgical techniques and postoperative management. And this attitude became more marked in the early 21 st century after surgeons began to perform mass OPCABG operations. ${ }^{(1)}$ This attitude was also reflected in the creation of special instruments and techniques for performing OPCABG operations in patients with LMCA disease. $^{(2)}$

In general, the initial period of performing OPCABG operations is characterized by a low proportion of high-risk patients (LMCA disease, low LVEF, dilated left ventricle, etc.), as well as a low number of patients with ACS, combined pathology of the lungs and kidneys, etc. ${ }^{(3-5)}$ For example, E.Buffalo et al. ${ }^{(4)}$ report a mean number of grafts per patient of 1.9 , and the proportion of OPCABGs in the total number of isolated $\mathrm{CABG}$ was $46 \%$. In general, the initial experience of performing OPCABG operations (performed generally in low-risk patients), based on numerous studies, could not convincingly demonstrate the advantages over performing such procedures on-pump. ${ }^{(5-8)}$ During the same period, the first reports on the results of OPCABG in high-risk patients appeared. ${ }^{(9)}$ The milestone work was published by J.Puskas et al., ${ }^{(10)}$ which convincingly demonstrated the advantages of OPCABG over on-pump CABG in high-risk patients. For the first time, the advantages of OPCABG operations in a highrisk group were demonstrated when comparison of patients by preoperative risk index was attempted.

We present a consecutive series of patients subjected to isolated OPCABG, which reflects the daily practice of our group. According to the main clinical and demographic parameters, patient characteristics in both groups were relatively homogeneous. As in most other series, a significant proportion of patients were males, although the average age of our patients (about 60 years in both groups) was lower than those of most other authors. More than $70 \%$ of patients in both groups had a history of MI, and there were no differences with respect to this factor between the groups. The vast majority of patients in both groups were in NYHA functional classes III and IV, as well as in the III-IV functional classes of angina pectoris by CCA. However, there were significantly more patients with ACS (25\% vs. $8.9 \%)$ in Group 1, which in our opinion was due to the specificity of coronary artery disease in patients of this group.

We detected some difference in the coronary region from which the myocardial revascularization was started. In $69 \%$ of cases in Group 1 and 83\% in Group 2, revascularization started with the LAD artery. This index was lower in Group 1, because they had more occlusive lesions of the RCA region, from which we had to start revascularization.

One of the criteria for the effectiveness of performing OPCABG is the proportion of such operations in the total number of all isolated CABG operations. This proportion varies from $49 \%$ to $99 \%$, according to the reports from different authors. ${ }^{(3-7,70,11)}$ Leading groups in this area, such as J.Puskas' group, perform OPCABG operations in $99 \%$ of all cases. In our series of 300 isolated CABG operations, $270(90 \%)$ were performed off-pump. Of these, some of the patients were initially distributed to have the operation onpump, and other patients, who were initially planned for OPCABG, were intraoperatively converted to on-pump CABG. On average, the rate of conversion varies from $1 \%$ to $15 \%{ }^{(3,9-12)}$ In our series of operations, this indicator was 3.2\% and $4.8 \%$ in Groups I and II, respectively. Our results are also within the limits of the values achieved by other groups.

The main argument against performing OPCABG operations that opponents of this method put forward is incomplete revascularization. In some studies, the average number of distal anastomoses per patient in OPCABG procedures was less than in similar patients subjected to conventional on-pump CABG. Such data may indicate whether the results were due to selection bias or true incomplete revascularization of patients. So, in the reports published by W. Turner et al., ${ }^{(3)}$ in a series of 100 operations the average number of distal anastomoses per patient was 1.9, and in E.Buffalo's series ${ }^{(4)}$ of 3,866 operations, this indicator was also 1.9. M. Emmert et al. ${ }^{(11)}$ report 3.62 distal anastomoses per patient in their series of OPCABG operations. The mean number of distal anastomoses per patient in our series was 3.07 and 3.02 in Groups 1 and 2, respectively, which may indicate the absence of a selection bias and a sufficiently high rate of complete revascularization cases (considering the number of patients with two- and three-vessel coronary lesions).

As can be seen in Table 3, according to the main parameters of the postoperative period, the results of operations in both groups were similar. According to the frequency of need for inotropic support, the time of respiratory support and the frequency and volume of plasma- and hemotransfusion, the parameters in the two groups did not differ. The AF frequency was $5.6 \%$ and $6.2 \%$ in Groups 1 and 2, respectively, a statistically insignificant difference. As is known, the rate of $\mathrm{AF}$ in the postoperative period after conventional onpump CABG operations varies within the range of $30 \%-45 \%$. According to various authors, after OPCABG surgery, AF occurs in $4 \%-26 \%$ of cases. Our results were also at the lower boundary of the given spectrum.

In addition, we did not find a significant difference in the incidence of non-fatal complications (perioperative MI, neurological disorders, bleeding, etc.) in the groups. Hospital 
mortality was $0.8 \%$ and $0.7 \%$ in Groups 1 and 2 , respectively. At the same time, the risk of surgical intervention calculated by the risk-calculator EuroScore was $4.63 \%$ for the patients of Group 1 and $3.83 \%$ for the patients of Group 2. J. Puskas et al., ${ }^{(10)}$ as well as A. Parolari et al. ${ }^{(13)}$ and YN Youn et al, ${ }^{(18)}$ gave the same difference of the risk of operative intervention predicted by the EuroScore calculator and actual mortality after OPCABG surgery. Our results of hospital mortality are within the limits of data given by other authors. ${ }^{(3-5,7,10)}$

\section{Conclusion}

Thus, the presence of left main stem lesion of LCA is not an additional risk factor that would complicate the performance of OPCABG surgery. The OPCABG operation in this group of patients is a safe method and can be performed without compromising the completeness of myocardial revascularization with the same low mortality as in low-risk patients.

\section{Study limitations}

The retrospective nature of this study makes it difficult for the authors to draw any definite conclusions. In addition, the number of patients in both groups is relatively small, which may reduce the statistical reliability of the results obtained, or a possible difference is not apparent due to the small number of cases. Nevertheless, the results we obtained clearly demonstrate the safety of performing OPCABG surgery in patients with LMCA disease.

\section{Competing interests}

The authors declare that they have no competing interests.

\section{References}

1. Cartier R. Off pump coronary artery bypass surgery. 1st ed. Georgetown: Landes Bioscience; 2005.

2. Singh SK, Kumar A, Rajput N, Devenraj V, Kumar S, Goyal T, Lal Sahni J. A novel cardiac positioning device for left main coronary artery stenosis. Ann Thorac Surg. 2012; 93(2):682-3. doi: 10.1016/j.athoracsur.2011.09.067.
3. Turner WF Jr. "Off-pump" coronary artery bypass grafting: the first one hundred cases of the Rose City experience. Ann Thorac Surg. 1999; 68(4):1482-5.

4. Buffolo E, Branco JN, Gerola LR, Aguiar LF, Teles CA, Palma JH, Catani R. Off-pump myocardial revascularization: critical analysis of 23 years' experience in 3,866 patients. Ann Thorac Surg. 2006;81(1):85-9.

5. Sellke FW, Chu LM, Cohn WE. Current state of surgical myocardial revascularization. Circ J. 2010;74(6):1031-7.

6. Kim KB, Kim JS, Kang HJ, Koo BK, Kim HS, Oh BH, Park YB. Ten-year experience with off-pump coronary artery bypass grafting: lessons learned from early postoperative angiography. J Thorac Cardiovasc Surg. 2010;139(2):256-62. doi: 10.1016/j.jtcvs.2009.08.040.

7. Godinho AS, Alves AS, Pereira AJ, Pereira TS. On-pump versus off-pump coronary-artery bypass surgery: a metaanalysis. Arq Bras Cardiol. 2012;98(1): 87-94.

8. Yaku H, Doi K, Okawa K. Off-pump coronary artery bypass grafting revisited: experience and evidence from Japan. Ann Thorac Cardiovasc Surg. 2013;19(2):83-94.

9. Chamberlain MH, Ascione R, Reeves BC, Angelini GD. Evaluation of the effectiveness of off-pump coronary artery bypass grafting in high-risk patients: an observational study. Ann Thorac Surg. 2002;73(6):1866-73.

10. Puskas JD, Thourani VH, Kilgo P, Cooper W, Vassiliades $\mathrm{T}$, Vega JD, at al. Off-pump coronary artery bypass disproportionately benefits high-risk patients. Ann Thorac Surg. 2009;88(4):1142-7. doi: 10.1016/j.athoracsur.2009.04.135.

11. Emmert MY, Salzberg SP, Seifert B, Schurr UP, Hoerstrup SP, Reuthebuch O, Genoni M. Routine off-pump coronary artery bypass grafting is safe and feasible in high-risk patients with left main disease. Ann Thorac Surg. 2010; 9(4):1125-30. doi: 10.1016/j.athoracsur.2009.12.059.

12. Stamou SC, Corso PJ. Coronary revascularization without cardiopulmonary bypass in high-risk patients: a route to the future. Ann Thorac Surg. 2001;71(3):1056-61.

13. Parolari A, Pesce LL, Trezzi M, Loardi C, Kassem $\mathrm{S}$, Brambillasca $\mathrm{C}$, et al. Performance of EuroSCORE in CABG and off-pump coronary artery bypass grafting: single institution experience and meta-analysis. Eur Heart J. 2009; 30(3):297-304. doi: 10.1093/eurheartj/ehn581.

14. Youn YN, Kwak YL, Yoo KJ. Can the EuroSCORE predict the early and mid-term mortality after off-pump coronary artery bypass grafting? Ann Thorac Surg. 2007;83(6):2111-17. 